\title{
VALERIO CORTÉS DEL REY, FUNDADOR DEL ÚNICO MAYORAZGO DE LA NUEVA VIZCAYA EN EL SIGLO XVII ${ }^{1}$
}

\author{
POR
}

\author{
CHANTAL CRAMAUSSEL
}

El Colegio de Michoacán, México

Valerio Cortés del Rey pertenecía a la pequeña nobleza de la ciudad de Zaragoza. Arribó al Nuevo Mundo en 1621 y ascendió con notable celeridad todos los peldaños de la sociedad. Mientras trabajaba de barretero, guardaminas, ensayador, prestamista, etcétera, adquirió numerosos bienes y propiedades situadas en la frontera norte de la provincia de Santa Bárbara. En la cúspide del éxito, logró un mayorazgo que estuvo en manos de sus descendientes hasta el siglo XIX. La biografía de Valerio Cortés del Rey es una muestra de la gran movilidad social al alcance de los peninsulares que se aventuraban a hacer fortuna en la gobernación de la Nueva Vizcaya.

Palabras clave: Nueva Vizcaya, mayorazgo, Parral, hacienda, frontera.

La Nueva Vizcaya, creada en 1562, comprendía a mediados del siglo XVII un inmenso territorio cuyas fronteras hacia el norte permanecían imprecisas

1 Una primera versión de ese ensayo fue publicada en Cramaussel, 18 (Chihuahua, 1992): 24-28. Reuní posteriormente más datos sobre Valerio Cortés del Rey que se encuentran dispersos en Cramaussel, 2006; se incluye en este texto un resumen biográfico escueto del personaje: 402-404. En el presente artículo retomo también de ese libro la información que me permite contextualizar la historia de la vida de Valerio Cortés del Rey. Se ofrecen otros datos, un primer mapa del mayorazgo, así como la trascripción de inventarios, avalúos y testamentos, y un estudio genealógico de la familia Cortés del Rey en Baca y Soto, 2006. Para un análisis de los bienes del mayorazgo en el siglo XVIII, con énfasis en la historia del arte, ver Curiel, 1993. Porras Muñoz, 1993: 21-22 da información complementaria. A este libro le fueron quitadas las notas entregadas por el autor, pero contiene ya la primera información precisa sobre la conformación del mayorazgo. Consultó, al parecer, las informaciones de testigos para solicitar licencia para fundar el mayorazgo, realizadas en 1670 y 1671, que se encuentran en el Archivo General de Indias, Sevilla (AGI), Guadalajara, legajo 34, r. 3, n. ${ }^{\circ}$ 7. Este documento es citado en Porras Muñoz, 1980a: 352. 
salvo en sus colindancias con la gobernación del Nuevo México, en la zona de El Paso. Hacia el sur, esta gobernación se extendía hasta la provincia de Acaponeta, en Nueva Galicia, y llegaba no muy lejos de Zacatecas. A partir de 1621, Durango, capital de la Nueva Vizcaya, pasó a ser también sede de un nuevo obispado ${ }^{2}$. Pero de hecho, las jurisdicciones civil y eclesiástica pretendían ejercerse sobre muy vastas regiones que permanecerían durante mucho tiempo fuera del control español. La colonización en el norte de la Nueva España fue muy lenta, de hecho, las diferentes provincias de la Nueva Vizcaya eran enclaves en suelo de indios infieles en el siglo XVII.

Como lo revelan los catálogos de Pasajeros a Indias, muy pocas eran las personas que se dirigían directamente al Septentrión de la Nueva España. Sin embargo, esa enorme región representaba una tierra de oportunidades para algunos individuos. La vida de Valerio Cortés del Rey es una muestra de la gran movilidad social al alcance de los peninsulares sin muchos escrúpulos que se aventuraban a probar suerte en Nueva Vizcaya. Nuestro personaje supo extraer provecho de las grandes distancias que separaban la provincia de Santa Bárbara de los centros de poder coloniales, y sacó partido también de las constantes guerras con los indios que hacían del Septentrión Novohispano un destino poco atractivo para la mayoría de los llegados de la reinos peninsulares, a pesar de los sonados descubrimientos mineros de Zacatecas en 1546, de San Luís Potosí en 1592 y de Parral en 1631.

En el siglo XVII, la Nueva Vizcaya se había vuelto un asilo para todos los indeseables de la Nueva España, ya que, para poblarlo, lo que más falta hacía eran hombres dispuestos a defender los pequeños enclaves coloniales de los infieles. Los indios gentiles rebasaban en cantidad a los pocos pobladores españoles y a sus aliados, los miembros de las castas y los indios de paz provenientes del centro o del occidente del virreinato, de modo que la amenaza de ser arrasados por los nativos indómitos fue constante durante toda la época virreinal en todos los poblados fundados a lo largo y lo ancho del Septentrión ${ }^{3}$.

Asegurarse la lealtad de los maleantes huidos, ofreciéndoles refugio y protección política, o hacer tratos personales con los gentiles para garantizar la paz, aseguraba el éxito de los colonos. Valerio Cortés del Rey era un hombre astuto que comprendió muy rápidamente esos mecanismos de ascenso social propios de la frontera. Llegó a ser uno de los personajes más ricos y poderosos de la Nueva Vizcaya en los años sesenta del siglo XVII, cuando se le consideraba nada menos que «la llave del reino». La Corona española lo recompensó

\footnotetext{
2 Sobre las jurisdicciones civiles y eclesiásticas, Porras Muñoz, 1980 b.

3 He insistido sobre la importancia de la relación demográfica entre españoles e indios en Cramaussel, 2006.
} 
por sus servicios al rey y autorizó en 1689 la fundación de un mayorazgo del que se beneficiaron sus descendientes durante más de una centuria.

\section{DE ZARAGOZA AL ÁRIDO NORTE}

La familia Del Rey pertenecía a la pequeña nobleza de la ciudad de Zaragoza, en el reino de Aragón, y ostentaba un escudo de armas. Valero del Rey Mayor e Ysabel Pabla Martínez fallecieron, al parecer, antes de 1631, fecha en la que dos de sus hijos se embarcaron hacia las Indias: Valerio tenía veinte años y Dionisio treinta. En la prueba de hidalguía de Valerio, con información de testigos notariada que se elaboró en Zaragoza en mayo de 1631, se certificó que todos los miembros de su familia eran cristianos viejos, «sin mancha de judíos, moros ni nuevos convertidos», y que su abuelo Juan del Rey había sido familiar del Santo Oficio durante los catorce años que antecedieron a su muerte. Ningún pariente de Valerio había sido condenado por la justicia ni había ejercido un oficio vil ni mecánico. Además, todos atestiguaron que Valerio era soltero. En ese documento, que acompaña la licencia de la Casa de la Contratación para pasar al Nuevo Mundo, no aparece nuestro personaje con el nombre de pila de «Valerio», sino con el más aragonés de «Valero». Tampoco tiene el apellido «Cortés», que ya llevaba su hermano Dionisio al zarpar de Sevilla en el verano de 1631 y que él mismo se pondría una vez en Indias.

La licencia data del 6 de junio de ese año y había sido solicitada por el prior del convento agustino de Sevilla, quien pedía permiso para que se fuera un grupo de doce frailes, encabezados por el maestro fray Pedro de Santa María, a la provincia de Michoacán, en la Nueva España. Uno de ellos se llamaba Dionisio Cortés del Rey; era «moreno de rostro, de buena estatura con una señal de herida sobre el ojo derecho». Su hermano Valero iba a viajar en calidad de criado de fray Pedro de Santa María. Se le describía como mozo «de veinte años, poco más o menos, de mediana estatura, moreno, de color quebrado, pequeños ojos, nariz algo gorda, con una peca negra encima el labio de la parte derecha y una herida en la cabeza sobre el copete de la parte derecha» ${ }^{4}$. Al parecer, con excepción de Valerio, todos los demás hijos de Valero del Rey e Isabel Martínez pertenecieron a la orden de los agustinos; María Paula e Isabel fueron monjas profesas del convento del Santo Sepulcro en Zaragoza, España ${ }^{5}$. Tal vez huérfanos a temprana edad, a ninguno de los cuatro hermanos les

4 Pedro de Santa María, 6 de junio de 1631, AGI, Casa de Contratación, legajo 5412, n. ${ }^{\circ}$ 43. Consultado en el portal Pares del Ministerio de Cultura de España.

5 Baca y Soto, 2006: 33. Estos autores retoman los datos que les proporcionó Carlos Yturralde, quien consultó el documento intitulado Probanza de las calidades de limpieza y nobleza 
alcanzó el capital heredado de sus progenitores para establecerse por cuenta propia o para buscar un buen partido en la península.

Las biografías de Dionisio y Valerio Cortés del Rey muestran que ambos eran, sin duda, muy ambiciosos. Apenas llegados al Nuevo Mundo, quizá en el otoño de 1631, se enteraron del descubrimiento de las minas de Parral, en el norte de la Nueva Vizcaya, ocurrido en el mes de julio anterior. Dionisio abandonó en seguida la idea de establecerse en Michoacán y, junto con su hermano menor, quien tampoco quiso quedarse al servicio de fray Juan de Santa María, tomó el Camino Real de tierra adentro para alcanzar la provincia de Santa Bárbara. En 1632, Dionisio abrió en ella una planta de beneficio de plata por cuenta de la orden de San Agustín, que llamó San Nicolás ${ }^{6}$. Ubicó esta hacienda en una estancia agrícola y ganadera que registró a su nombre y puso bajo la advocación de Santiago ${ }^{7}$. La prontitud con la que se trasladaron los dos hermanos a la provincia de Santa Bárbara, que estaba a dos o tres meses de viaje de México, para crear esas haciendas es sorprendente. Quizá aprovecharon la ida de una de las caravanas que solían partir de México a fines de septiembre ${ }^{8}$. Pero disponían, sin duda, de caudal previo, y tal vez incluso de un préstamo de los agustinos, ya que la hacienda de San Nicolás perteneció al convento de Durango de la orden de San Agustín. Las propiedades de fray Dionisio se encontraban a unas cinco leguas de Parral y no muy lejos de la villa de Santa Bárbara, que había dado nombre a la provincia creada en 1567 en la cuenca del río Florido.

Los hermanos Cortés del Rey llegaron a la provincia de Santa Bárbara en el mejor momento. El poblamiento de Parral fue fulgurante. Incluso el gobernador de la Nueva Vizcaya se trasladó a ese centro minero y, cuando anunció el surgimiento del nuevo real al rey de España en enero de 1632, el asentamiento contaba ya con mil doscientos habitantes ${ }^{9}$. Su población total rebasaría

y demás requisitos del general don Juan Cortés del Rey natural del real de San José del Parral en Indias en la Nueva Vizcaya, pretendiente del hábito de la Orden de Santiago, 1688, Archivo Histórico Nacional, Madrid (AHN), cajón 70, n. ${ }^{\circ}$ 80, exp. 2176. A fines del siglo XVII figuraban en la hacienda de Valerio Cortés los retratos de sus dos hermanas que se habían quedado en España. En 1675 un «Maestro Fr. Joseph Ximeno Cortés del Rey, de la provincia de Aragón» pide pasar al reino de Granada para evangelizar a los naturales con ocho religiosos y un criado originario de Zaragoza. AGI, Casa de Contratación, legajo 5440, n. ${ }^{\circ}$ 2, r. 116.

${ }^{6}$ La pertenencia de una hacienda de beneficio de metales a una orden regular no debe sorprendernos. Varios eran también los jesuitas que tenían minas, como en Sonora, por ejemplo.

7 Baca y Soto, 2006: 30. Escritura de venta de una hacienda de sacar plata por fundición ubicada en la hacienda de Santiago, que fundó Dionisio Cortés del Rey, que hace el convento de San Agustín de Durango en dos mil pesos a Valerio Cortés del Rey.

8 Acerca de los caminos hacia la provincia y el transporte, Cramaussel, 2006: 15-20.

9 Porras Muñoz, 1988: 50. 
los cinco mil individuos diez años después ${ }^{10}$. Bajo el impulso de las minas de Parral, la producción en plata de la Nueva Vizcaya se multiplicó por diez en la década que siguió al descubrimiento de la veta madre, llamada «La Negrita» ${ }^{11}$. No había habido bonanza minera más marcada en el Septentrión Novohispano desde que se descubrió Zacatecas en $1546^{12}$.

En un principio, Valerio Cortés del Rey no pareció destinado a ser uno de los oligarcas más prósperos de la provincia de Santa Bárbara. Trabajó algunos meses de barretero en las minas de Parral en 1632, pero pronto dejó la provincia de Santa Bárbara para fungir como guarda-minas en el real de San Luís Potosí, en auge desde 1620. Retornó a la provincia de Santa Bárbara en el séquito del gobernador Luis de Valdés ${ }^{13}$ en 1644, después de comprar en México el cargo de ensayador y balanzario de las minas de Parral ${ }^{14}$. Este oficio, que ejerció durante veintidós años, le permitió tener ingresos regulares e importantes, pues cobraba uno por ciento sobre todos los metales ensayados, sin contar que ocultaba el contenido en oro de los minerales producidos a cambio de alguna retribución por parte de los mineros beneficiados. Dos años después, en 1646, Valerio Cortés del Rey compró el abasto de carne de res y de borrego de Parral. Aprovechó, sin duda, los rebaños que estaban todavía en manos de su hermano Dionisio para poder pretender ese monopolio. Parral se encontraba entonces en su época de esplendor: en la cuenca del río Florido vivían más de veinte mil personas ${ }^{15}$ y ser beneficiado de la carne era una manera segura de obtener jugosas ganancias. Valerio Cortés logró conservar también el privilegio del abasto de res y borrego durante largos años: de 1646 a 1667. En 1675, lo adquirió de nuevo sin tener que desembolsar un solo real por tres años más; a cambio, se comprometió a reconstruir la iglesia parroquial, obra que le costó diez mil pesos ${ }^{16}$.

Dionisio quedó a la cabeza de las haciendas de San Nicolás y Santiago hasta probablemente su muerte, acaecida en 1655. Tras su fallecimiento, Valerio Cortés compró la primera de ellas a la orden de los agustinos y heredó las tierras y el ganado de la hacienda de Santiago. Pero no le bastaron esos bienes;

10 Cramaussel, 2006: 148-149.

11 Escribí la biografía del descubridor de la veta madre de Parral en Cramaussel, 1992.

12 Álvarez, 1989: 105-139.

13 Cramaussel, 2006: 402.

14 Nombramiento de ensayador y balanzario de las minas del Parral para el alférez Valerio Cortés del Rey, Archivo General de la Nación, México (AGN), 6 de enero de 1644, Cédulas reales, vol. 15, exp. 2 (citado por Porras Muñoz, 1980a: 352). Se interroga a Valerio Cortés en San Luís Potosí en 1644.

15 Cramaussel, 2006: 148.

16 Cramaussel, 2006: 402-404. 
nuestro personaje era un hombre con muchas iniciativas, incansable en su ansia de reunir poder y dinero en todos los frentes posibles.

Al mediar el siglo, Valerio Cortés del Rey tenía ya cuarenta años de edad; había entrado, por lo tanto, en una etapa madura que para muchos varones de la época estaba cercana a la muerte. Pero su vida, que duraría cuatro décadas más, tomó entonces un nuevo rumbo que lo llevaría a ser el hacendado más encumbrado de la región. Los hombres ricos siempre han representado un buen partido, aunque estén avanzados en edad, de modo que también le sonrió la suerte a Valerio al contraer matrimonio el 11 de diciembre de 1653 con Magdalena de Chavarría, hija de Juan de Chavarría ${ }^{17}$, el opulento mercader que transportaba la plata del rey en el real de San José del Parral. Valerio Cortés llevaba entonces nueve años con el oficio de ensayador y era beneficiado de la carne desde hacía siete años. La novia, diecinueve años menor que él, estaba preñada de tres meses el día de la boda, pero las relaciones sexuales eran permitidas a los que se habían dado palabra de casamiento y nadie, ni siquiera Valerio Cortés, se podía burlar de la hija de un mercader de plata que tenía importantes conexiones en todo el virreinato. Aunque es probable que también ese embarazo fuera la mejor manera de convencer a su futuro suegro de la conveniencia de la unión matrimonial. Juan Cortés del Rey (el cual recibió el nombre de pila que era, al mismo tiempo, el de su abuelo materno y el de su bisabuelo paterno) nació seis meses después de la boda de sus padres: el 5 de junio de 1654. Le seguiría Teresa, la cual vio la luz el 11 de marzo de 1656, y después Valerio, nacido el 14 de julio de 1659.

Valerio Cortés del Rey acumuló bienes, cargos y honores tanto en lo civil como en lo militar y en lo eclesiástico. Era ya alférez en 1650 y el gobernador Enrique Dávila Pacheco, quien sucedió a Luis de Valdés, lo hizo capitán y sargento mayor por sus méritos en la guerra. Ejerció ese cargo durante trece años sin goce de sueldo ${ }^{18}$. Cortés del Rey se había vuelto indispensable durante todas las contiendas con los indios; desde los años cuarenta, se le acusaba de tener mucho ascendente sobre ellos porque, al decir de los vecinos de Parral, le obedecían más a él que a las autoridades locales. Así sucedió también en 1666-1667: «los tobosos de su hacienda no conocen más gobernador que él, si iban a la guerra no iban por el gobernador sino por él» ${ }^{19}$. El oligarca albergaba a muchos naturales en sus dominios. Unos provenían de su pueblo de indios de

17 «Chavarría» es la forma castellanizada del apellido vasco Echevarría o Echeverría. Las tres grafías se encuentran en la documentación consultada.

18 AGI, Guadalajara, legajo 14, r. 3, n. ${ }^{\circ} 7$.

19 Juicio de residencia de Antonio de Oca y Sarmiento, 1667, AGI, Escribanía de Cámara, legajo 396a, f. 210. Testimonio de Francisco Montaño. 
encomienda de San Luis Babiseomalva ${ }^{20}$, en las riveras del río Conchos. Otros eran originarios del norte de la provincia de Santa Bárbara y habían sido atraídos por el capellán de la hacienda, al que el obispo encargó la evangelización de los nativos allende el río San Pedro, como se verá más adelante. Otros más eran presas de guerra que el caudillo había tomado durante las razzias en los pueblos de infieles y que había criado desde niños en su hacienda. Los indios que habitaban en los dominios de Valerio Cortés del Rey estaban dispuestos a guerrear junto con su amo, ya que éste los protegía de ser repartidos en las haciendas mineras. En tanto que sirvientes, dejaban de estar sujetos al repartimiento impuesto a todos los indios de la Nueva Vizcaya, los cuales no tributaban al rey en especie sino en trabajo forzado a razón de cuatro a seis semanas por año ${ }^{21}$.

Una vez en campaña, los jefes militares de la provincia de Santa Bárbara no acataban órdenes de nadie más, como lo muestra la burlona respuesta de Valerio Cortés a los consejos militares del gobernador Luis de Valdés: «lo hacían niño volviendo a la primera edad y haciéndole venir a la escuela [...] que llevase al diablo el alma de las órdenes ${ }^{22}$. Cada vez que se les presentaba la ocasión, los caudillos hacían recordar su protagonismo en las campañas contra los rebeldes para defender su estatuto de privilegiados ante las autoridades locales. Sólo ellos contaban con tropas fieles, pues los indios auxiliares provenientes de las misiones se pasaban al enemigo con demasiada facilidad y los pobladores recién llegados, muchos de ellos sin experiencia en la guerra y que desconocían la región, no eran tampoco combatientes ideales. Además, desplazar tropas durante meses implicaba también gastos en comida, armas y pólvora que únicamente los hacendados podían sufragar. Por otra parte, Valerio Cortés conocía personalmente no sólo a los sirvientes indígenas de sus haciendas, sino también a muchos de los infieles que moraban en los contornos de las zonas colonizadas por los españoles. Parece incluso que, en ocasiones, tomaba partido por ellos. En 1667, los jesuitas lo acusaron de ser aliado de los rebeldes que habían matado a varios neófitos de la misión de Satevó en ausencia de

20 Merced hecha por Franciso Gorráez y Beaumonte, de indios a Valerio Cortés del Rey y su hijo Juan, hecha en 1675 ante Diego de Galarreta, citada en Griffen, 1979: 63. Como lo señalan Baca y Soto, 2006: 14, la fecha indicada en el traslado del documento original es errónea.

21 Sobre los sistemas de trabajo, y en especial la encomienda y el repartimiento en el Septentrión Novohispano, ver Cramaussel, 2006: 205-219. En los hechos, eran compelidos a laborar durante mucho más tiempo, cuando no se endeudaban de por vida.

22 Juicio de residencia de Antonio de Oca y Sarmiento, 1667, AGI, Escribanía de Cámara, legajo 396a, f. 210. Testimonio de Francisco Montaño. 
su ministro. Los padres afirmaban que había «indicios evidentes de cómo el dicho Valerio Cortés tiene coligación con los indios» ${ }^{23}$.

Pero no todas las tropas con las que contaba Valerio Cortés del Rey estaban compuestas por indios. También las integraban sus sirvientes de sangre mezclada: se trataba de centenares de incondicionales «mulatos y mestizos [...] gente facinerosa que sólo pueden asistir en aquellas partes». Les daba refugio en su hacienda, por lo cual se decía que era «amigo de traer mestizos y mulatos, gente ruin ${ }^{24}$. El oligarca ejercía funciones de patriarca sobre su amplia «familia», de la que formaban parte todos sus sirvientes permanentes y sus esclavos, tanto indios como mulatos y mestizos. Los alimentaba y los vestía a título de salario y les daba regalos de Navidad. También era él quien pagaba los gastos correspondientes a todos los ritos cristianos de pasaje de los que moraban en sus haciendas: bautizo, matrimonio y entierro. Se decía de sus indígenas que lo consideraban como «el padre de la región en razón de su gran fortuna» ${ }^{25}$. La magnificencia de las fiestas religiosas que se celebraban en las capillas de su propiedad dependía en efecto de la generosidad del oligarca. Sin embargo, el hacendado no valoraba de manera semejante a todos los residentes en sus dominios.

En las haciendas de Cortés del Rey había también esclavos: en su fábrica de jabón, en su obraje de lana en la hacienda de San Antonio de Padua y en su hacienda de beneficiar plata de Santiago. Y como los demás hacendados, ejercía la justicia sobre ellos. La Corona sólo se reservaba el derecho de condena a la pena capital. El magnate poseía una cárcel privada en Santiago y trataba cruelmente también a sus operarios mineros, que solía encerrar en las galerías donde laboraban de día y noche; había colocado en la entrada de cada socavón un palo llamado «el bramadero» en el que ataba a los recalcitrantes para azo$\operatorname{tarlos}^{26}$. En la planta de beneficio de Santiago, los indios reducidos a la esclavitud trabajaban en el mortero, donde mezclaban el azogue con el mineral hecho polvo hasta que no podían sostenerse en pie. Eran naturales cogidos en la guerra a los que se conmutaba la pena de muerte por el trabajo forzado que los condenaba al exterminio lento a causa del polvo de los metales y, sobre todo,

23 Juicio de residencia de Antonio de Oca y Sarmiento, 1667, AGI, Escribanía de Cámara, legajo 396b, f. $160 \mathrm{v}$.

24 Juicio de residencia de Antonio de Oca y Sarmiento, 1668, AGI, Escribanía de Cámara, legajo 394a. Testimonio de Diego de Alarcón Fajardo y de Gaspar de Quesada.

25 Juicio de residencia de Antonio de Oca y Sarmiento, 1667, AGI, Escribanía de Cámara, legajo 396a. Testimonio de Ambrosio Sáenz.

26 Juicio de residencia de Antonio de Oca y Sarmiento, 1666, AGI, Escribanía de Cámara, legajo 396b. 
por los venenosos vapores del mercurio. Junto con ellos, laboraban delincuentes de todo tipo, negros y miembros de las castas, y todos eran tratados sin piedad porque: «Los esclavos que se venden para dicha hacienda son de calidad que sin mucho miedo y castigo no hay quien se averigüe con ellos porque cada día huyen ${ }^{27}$.

\section{CORTÉS: «LA LLAVE DEL REINO»}

El poder militar de Valerio Cortés era tal que podía mofarse de los gobernadores cuando no actuaban conforme a sus intereses. Con el tiempo se ganó la fama de ser enemigo de todos ellos. Enrique Dávila Pacheco, por ejemplo, pidió expresamente al juez de residencia no tomarle testimonio a Cortés porque lo creía capaz de «cortarle la honra y hacienda». Sin embargo, nuestro biografiado trataba siempre de aliarse, en un primer momento, con el gobernador de turno, como lo hizo de hecho con el gobernador Francisco de Gorráez y Beaumont (1660-1666), quien fue su compadre. Pero Gorráez pronto se relacionó con los enemigos de Cortés, quien, en venganza, lo apodó «Parolillo», «La arremangada Celestina» o «El Enfrenadillo.» Al entrar en litigio con los gobernadores nombrados por el virrey, que se quedaban sólo cinco o seis años en el cargo, los hacendados de la provincia de Santa Bárbara recurrían sistemáticamente para quejarse a los jueces vitalicios de la audiencia de Guadalajara, que constituían, de hecho, un contrapoder más estable, el cual limitaba las amplias prerrogativas del gobernador de la Nueva Vizcaya ${ }^{28}$. El mayor conflicto de ese tipo en el que fue involucrado Valerio Cortés del Rey estalló cuando el gobernador Antonio de Oca y Sarmiento (1666-1670), el cual quería monopolizar el comercio del real de San José del Parral, mandó cerrar su tienda y lo envió a prisión por ocultar el oro de los metales que extraía en San Francisco del Oro. Junto con Cortés, varios personajes prominentes de la provincia de Santa Bárbara, que habían sido agraviados también por el gobernador, apelaron ante la Audiencia de Guadalajara, la cual ordenó la liberación de Valerio Cortés del Rey, a quien designó, además, como juez de comisión para averiguar los abusos cometidos por Oca y Sarmiento. El Consejo de Indias, al que recurrió después el gobernador, falló en su contra y lo destituyó de su cargo antes de que terminara su periodo. Esta victoria fue festejada en Parral por Valerio Cortés, quien clamaba: «iYa cayó el gallego!»»29.

27 Juicio de residencia de Antonio de Oca y Sarmiento, 1667, AGI, Escribanía de Cámara, legajo 397b, n. ${ }^{\circ}$ 44. Testimonio de Ambrosio Sáenz.

28 Acerca de este punto, véase Porras Muñoz, 1980b.

29 Juicio de residencia de Antonio de Oca y Sarmiento, 1669, AGI, Escribanía de Cámara, 
El poder político de Valerio Cortés del Rey no descansaba solamente en su fuerza militar. Valerio no descuidó el comercio, ni la cría de ganado y la extracción de plata que habían hecho la fortuna inicial de su hermano. Para no depender de los mercaderes para el avío de sus haciendas, en 1667 abrió una tienda donde ofrecía todo tipo de géneros; el valor de su primer lote de mercancías alcanzó los cuarenta mil pesos ${ }^{30}$. En los años sesenta, Valerio Cortés del Rey se había vuelto «el minero más importante de la Nueva Vizcaya» a pesar de la decadencia de las minas de San José del Parral. De hecho, era el principal minero de San Diego de Minas Nuevas, descubiertas en 1634 a una legua de Parral, así como de San Francisco del Oro, centro minero abierto en 1666 que tuvo un corto pero marcado auge y estaba cerca de su hacienda de Santiago. Fue diputado de minas de ese último real repetidas veces ${ }^{31}$.

Como todos los hombres de la época, Cortés del Rey trataba de diversificar sus actividades para aumentar su caudal y lograr cierta autonomía en los negocios. Adquirió, así, extensas haciendas agrícolas que complementaban su riqueza ganadera y minera e incrementaban también su prestigio social. En varios de los pleitos que entabló en contra del gobernador de turno, sus enemigos denunciaron la manera de cómo había logrado tener tanto poder y de qué modo había ido construyendo su emporio en tan poco tiempo. Cortés del Rey disponía de los ingresos que le proporcionaban el abasto de la carne, el oficio de ensayador y el beneficio de la plata, pero también, al prestar dinero, se hizo de muchas propiedades de deudores insolventes: «Se hace dueño de las personas dándoles dinero, sujetándolas a la servidumbre, casi a esclavitud, poniéndoles prisiones en sus haciendas; a otros ocultándolos en ellas y a otro a título ansimismo de haberles dado dineros hacerles vender sus haciendas y adquirirlas por menos precio de lo que valen $»^{32}$.

A mediados del siglo XVII, Dionisio y Valerio Cortés mandaron pastar ganado en las riberas del río Conchos, donde se multiplicó de maravilla, con el

legajo 396b, f. 20v. Sobre los conflictos entre oligarcas y gobernadores, Cramaussel, 2006: 280-295.

30 Dionisio Cortés del Rey ya se había percatado del poder de los comerciantes: se quejaba en 1646 de que los mineros «dependen tanto de los comerciantes que si estos no les entregan maíz, carne y velas y todo lo que necesitan las minas no pueden ser explotadas ni pobladas»: Visita del reino, Archivo Histórico de Parral, Chihuahua (AHP), 1646a, n. ${ }^{\circ}$ 48, testimonio de fray Dionisio Cortés. Sin embargo, Valerio Cortés no conservó por mucho tiempo su tienda, ya que no se encuentra mencionada entre sus bienes ni en 1670 ni en 1688.

31 Juicio de residencia de Antonio de Oca y Sarmiento, 1669, AGI, Escribanía de Cámara, legajo 396b, n. ${ }^{\circ}$ 8, ff. 231v y 232-233; AGI, Guadalajara, legajo 14, r. 3, n. ${ }^{\circ} 7$. Cramaussel, 2006: 300 .

32 Juicio de residencia de Antonio de Oca y Sarmiento, 1668, AGI, Escribanía de Cámara, legajo 396c, n. ${ }^{\circ} 11$. Testimonio de Domingo de la Puente. 
fin de solicitar después de la Corona sitios de ganado en esa misma región para legalizar la ocupación del suelo, tal y como se acostumbraba en aquel entonces ${ }^{33}$. Fue a orillas de ese río, en la hacienda agrícola-ganadera de Nuestra Señora del Pilar de Conchos (también llamada Nuestra Señora del Pilar de Zaragoza, advocación que recordaba la devoción principal de su ciudad natal), donde Valerio Cortés del Rey estableció su residencia en los años ochenta ${ }^{34}$. La hacienda se situaba en una zona particularmente fértil, donde abundaban las tierras aluviales. Como lo ilustra el mapa anexo, no muy lejos de allí estaba su pueblo de encomienda de indios conchos, llamado San Luis Babiseomalva, que le había sido otorgada en $1665^{35}$.

Valerio Cortés dejó de habitar la hacienda de Santiago, que estaba contaminada por los hornos de fundición y el mercurio, y donde laboraban los indios condenados al trabajo personal y los negros esclavos que encerraba el mayordomo cada noche junto a la casa del amo. Aunque los más peligrosos estaban con grillos, su propia presencia representaba siempre una amenaza ${ }^{36}$. En Pilar de Conchos sólo radicaban ocho esclavos de lujo: cuatro grandes y cuatro pequeños, que contribuían al prestigio social del amo; esos esclavos, que trabajaban sin duda en calidad de domésticos, fueron evaluados en 2.400 pesos en $1688^{37}$.

Varias eran las misiones fundadas décadas antes a lo largo del río Florido, del Conchos y del San Pedro que mandaban a los indios a laborar por vía de repartimiento a las haciendas de los españoles. Pero Valerio Cortés del Rey ya no dependió exclusivamente de la buena voluntad del gobernador de turno ni de la de los misioneros para obtener una mayor cantidad de trabajadores indios. En 1656, contrató por el enorme salario de mil pesos anuales a un joven jesuita expulso de Filipinas llamado Francisco de los Ríos, quien había sido

33 Cramaussel, 2006: 319-326; AGI, Guadalajara, legajo 34, r. 3, n. ${ }^{\circ} 7$.

34 En 1671 no se menciona esta hacienda entre sus bienes, pero ya era sede de su residencia en 1688; ver más adelante.

35 Este poblado se ubicaba en terrenos ahora cubiertos por la presa de La Boquilla: Escritura del 20 de agosto de 1665 en que se otorga la merced de los indios oloboyaguames que habian sido encomendados en 1645 a Francisco Montaño de la Cueva y en 1660 a Alonso Bello Montes de Oca, 1665, AHP, exp. 1989 (este documento está mencionado en Baca y Soto, 2006: 14). Utilizamos la clasificación nueva del archivo según el índice elaborado por Roberto Baca, en el que figura el número de expediente. En Nueva Vizcaya, el gobernador entregó títulos de encomiendas hasta 1670. Cramaussel, 2006: 186-205.

36 Cramaussel, 2006: 197-199.

37 Autos para avalúos de las propiedades que se incluyen en el vínculo y mayorazgo que funda Valerio Cortés del Rey, AHP, 1738b (exp. 4724), trascrito en Baca y Soto, 2006: 101. Una casa mediana en Parral, en el mismo momento, costaba alrededor de cuatrocientos pesos. 


\section{Ubicación del mayorazgo fundado por Valerio Cortés del Rey al norte de la provincia de Santa Bárbara}

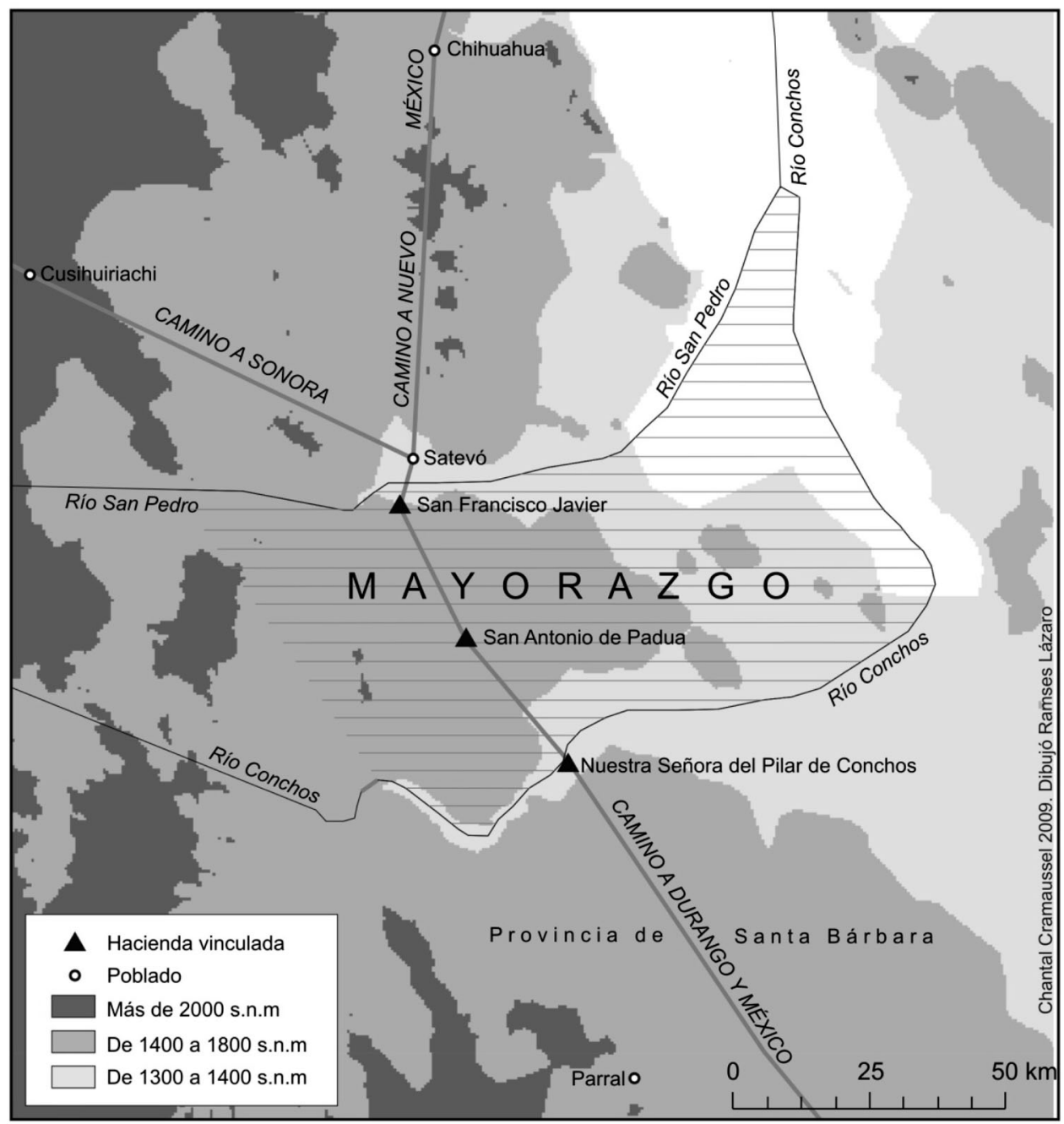

Mapa reelaborado con base en BACA, Roberto y SOTO, Rita, El Mayorazgo del Río de Conchos (Chihuahua, 1689-1838), Parral, Edición privada, 2006, p. 158.

ordenado en México cuatro años antes. Fue el gobernador Francisco de Gorráez el que se lo había recomendado. El hacendado le encomendó primero la educación de sus hijos hasta que en 1674 el obispo Escañuela le encargó también al maestro Ríos la evangelización de todos los indios allende el río San 
Pedro $^{38}$. Francisco de los Ríos no tenía la posibilidad de abrir misiones, pero sí podía atraer a los indios para que pasaran a radicar en las haciendas de su amo. Ese nombramiento disgustó, sin duda, a la orden de San Ignacio, que había fundado a principios de los años cuarenta las misiones de San Antonio de Satevó y Santa María de Cuevas al norte del río San Pedro.

De hecho, Valerio Cortés entró en conflicto con los jesuitas de la misión de Satevó, quienes se quejaban de que el ganado del hacendado destruía las milpas de los indios a su cargo. Lo acusaban también de pretender ampliar sus dominios sobre cuarenta leguas más, alegando que no respetaba las sesenta leguas (unos 240 kilómetros) que le habían sido otorgadas ${ }^{39}$. Francisco de los Ríos, además de fungir de preceptor y de «misionero» sin pertenecer a ninguna orden evangelizadora, ejercía la medicina sin tener título para ello. Este turbio personaje terminó, sin embargo, sus días como maestro arcediano, miembro del cabildo catedral de Durango y volvió a reconciliarse con los jesuitas, ya que dictó sus últimas voluntades al padre superior del Colegio de San Ignacio de la ciudad de Durango, cuidándose muy bien de silenciar su vida anterior $^{40}$. No quedó huella documental de su fecha y lugar de nacimiento ni de su vida en Filipinas. Sin embargo, salieron a la luz las malversaciones que había hecho con el dinero del diezmo y el robo del espolio del obispo Escañuela. El asunto había llegado hasta la audiencia y Francisco de los Ríos fue excomulgado, pero el obispo en turno lo exoneró de toda culpa, quizá para evitar un escándalo mayor. No cabe duda de que Valerio Cortés del Rey había encontrado al aliado ideal: hábil en política, con una ambición desmesurada, pocos escrúpulos y muy buenas relaciones con el obispo, que le permitía desafiar a las órdenes regulares y hacerse de indios. Pero si bien Cortés del Rey tuvo problemas con los jesuitas que se habían establecido cerca de sus haciendas, se cuidó de mantener siempre muy buenas relaciones con la Iglesia secular y la orden

38 Visita del obispo Escañuela, 1674, Biblioteca Nacional de Antropología e Historia, México (BNAH), microfilmes, Zacatecas; AGI, Juicio de residencia de Antonio de Oca y Sarmiento, 1666, Escribanía de Cámara, legajo 397a.

${ }^{39}$ Quejas de los indios del pueblo de Satevó en contra de Valerio Cortés del Rey por usurpación de propiedades, 1667, AHP, 1667b, exp. 2077. En realidad, los dominios de Valerio Cortés no se extendían sobre más de cien kilómetros, como lo muestra el mapa anexo del mayorazgo.

40 Autos del rector de la Compañía de Jesús, albacea de Francisco de los Ríos, 1700, Archivo Histórico del Arzobispado de Durango (AHAD), 102: 536-668 (en el microfilm). Al parecer, el arcediano Ríos fue también el padre de la extensa prole (tres hijos y cuatro hijas) de María de los Ríos, una sirvienta mulata a la que dona doscientos pesos para que «se vaya a buscar su vida» en 1700. El canónigo Ríos construyó una de las casas más ostentosas de la ciudad de Durango. Vallebueno, 2005: 196. 
franciscana, que poseía una serie de misiones a lo largo del río Conchos, en colindancia con los tobosos de guerra, al este de las haciendas de nuestro personaje. Valerio Cortés fue síndico del convento franciscano erigido en San Bartolomé y se encargó durante varios años también de recolectar el diezmo en ese mismo valle, que era el granero de la provincia en el siglo XVII. Ya aludimos también al donativo de diez mil pesos que otorgó Valerio Cortés para reparar el templo parroquial ${ }^{41}$.

Todas las haciendas de labor y de ganado de Valerio Cortés del Rey estaban ubicadas en lugares estratégicos: a la vera de los principales caminos y en frontera con los indios gentiles. Nuestra Señora del Pilar de Conchos, que comenzó a poblar con ganado en 1657, se ubicaba en el extremo norte de la provincia de Santa Bárbara ${ }^{42}$. En 1661, Cortés compró en las márgenes orientales de la misma provincia, a orillas del río Florido, la hacienda de Nuestra Señora de Huejuquilla a Domingo de Apresa, importante minero de la región, y la rebautizó San Valerio de Huejuquilla ${ }^{43}$. Huejuquilla lindaba con el altiplano desértico, habitado por los indios de guerra, quienes explotaban la saltierra necesaria para beneficiar la plata y en ciertas temporadas del año iban a pescar por la zona. La hacienda de San Gregorio ${ }^{44}$, de la que era propietario Valerio Cortés desde 1662, estaba en la ruta hacia Sonora y el Nuevo México, y por allí tenían que transitar todos los viajeros que venían de San Bartolomé y se dirigían hacia el norte. En el camino de Sonora, entre los ríos Conchos y San Pedro, nuestro personaje fundó la hacienda de San Antonio de Padua, y más al norte, a una legua del vado del río San Pedro, en un sitio donde pastaban ya 60.000 ovinos de su propiedad, Valerio obtuvo una merced de tierra que fue el origen de la hacienda de San Francisco Javier. El caudillo aseguraba así la paz de los caminos sobre cientos de kilómetros, así como el fácil traslado de mercancías e indios entre la provincia de Santa Bárbara, el Nuevo México y Sonora ${ }^{45}$. A partir de los años sesenta, el grueso de la mano de obra en el centro minero de Parral provenía de esas dos regiones y también parte del ganado que se consu-

41 Cramaussel, 2006: 402-404.

42 Valerio Cortés del Rey solicita se la ponga en posesión de unos terrenos comprados a Diego Romo de Vivar, 1660, AHP, 1660a, exp. 1723. Además obtuvo la merced de varios sitios en esa misma zona. Porras Muñoz, 1993: 21.

43 Baca y Soto, 2006: 30. No sabemos si se trata de la misma hacienda de Atotonilco que estaba despoblada en 1670 desde hacía cinco o seis años y pertenecía también a Valerio Cortés. AGI, Guadalajara, legajo 14, r. 3, n. ${ }^{\circ} 7$.

44 Redención de censo, 2 de enero de 1666, AHP, 1663a, Protocolos. Se menciona en este documento que Valerio Cortés compró esta hacienda a Felipe Montaño el 14 de abril de 1662.

45 Como él mismo quiso hacerlo constar en sus relaciones de méritos en 1671. AGI, Guadalajara, legajo 34 , r. 3 , n. ${ }^{\circ} 7$. 
mía en el centro minero tenía el mismo origen ${ }^{46}$. Valerio estaba, por lo tanto, en la mejor posición para negociar con los indios rebeldes que circundaban sus dominios. Por esta razón se ufanaba de ser «la llave del reino» y afirmaba que lo podía cerrar en cuanto se le antojara ${ }^{47}$. En 1688, dos años después del descubrimiento de las minas de Cusihuiriachi, adquirió una nueva merced de tierra al noroeste de ese nuevo real, donde su hijo Juan fundaría la estancia de La Laguna ${ }^{48}$.

\section{EXPRESIONES DEL PODER: LA CASA Y EL MAYORAZGO}

En la provincia de Santa Bárbara, los hacendados del siglo XVII solían vivir en sus haciendas agrícolas, pero poseían también una casa en Parral. Se facilitaban así sus actividades comerciales y, eventualmente, también sus relaciones con el gobernador y su séquito, que radicaban en el real de minas. La presencia de Valerio Cortés del Rey, como la de todos los personajes importantes de la región, era también requerida para las fiestas señaladas y los alardes de armas. En 1664, Valerio Cortés mandó edificar una casa principal en San José del Parral, la cual se asemejaba a un fuerte inexpugnable al decir del visitador de la Audiencia de Guadalajara Gárate y Francia, quien la requisó para alojarse en ella en 1669. Fue evaluada en 27.340 pesos en $1688^{49}$, cuando las moradas de más de cinco mil pesos en el centro minero eran excepcionales ${ }^{50}$. Las casas de Parral tenían fundaciones de piedra pero los muros, incluso los de las más ricas, eran de adobe. La única construida con muros y techo de ladrillos, con marcos de cal y canto en puertas y ventanas era la de nuestro personaje. En la entrada de la residencia, el hacendado había mandado labrar su escudo de armas ${ }^{51}$. El techo del edificio reposaba sobre

46 Su presencia en Parral fue mencionada por primera vez en el estudio pionero de West, 2002: 96-110. Ver también Cramaussel, 2006: 219-225.

47 Cramaussel, 2006: 403.

48 Otro distrito minero que data de principios del siglo XVIII a medio camino entre $\mathrm{Cu}$ sihuiriachi y Chihuahua. Título de denuncia de tierras adjudicadas en la jurisdicción de Cusihuiriachi a favor de Juan Cortés, AHP, 1668a, exp. 3025. Baca y Soto, 2006: 30. A esta estancia atribuyen estos autores el origen de la hacienda de Bustillos; sin embargo, Porras Muñoz afirma que el primer poblador fue José Sánchez de Chávez. Porras Muñoz, 1993: 31.

49 Baca y Soto, 2006: 103. Es un poco más del valor que se le atribuía en 1670; en esta última fecha fue estimada en 25.000 pesos. AGI, Guadalajara, legajo 14, r. 3, n. ${ }^{\circ} 7$.

50 Acerca de los diferentes tipos de casas en Parral y su valor respectivo: Cramaussel, 2006: 120-130.

51 Se conserva aún en Parral junto con parte de la fachada, pero la casa del siglo XVII ha sido demolida. 
vigas que estaban cubiertas con tejamanil afianzado con clavos, muy caros a razón del alto precio del metal importado todo de España. Contrariamente también a las demás casas principales del real, cuyas ventanas miraban a la calle, las de Cortés daban casi todas a un patio interior y barrotes de hierro protegían la única ventana que abría hacia la vía pública. No todas las doce piezas dispuestas alrededor del patio de la casa de Valerio en Parral tenían ventana; la mayoría contaba únicamente con una gran puerta de dos manos que quizá permanecía abierta en el día para dejar entrar la luz y asegurar una mejor ventilación ${ }^{52}$.

Los objetos que amueblaban y adornaban el interior eran dignos del caudal del dueño. Se evaluaron en poco más de diez mil pesos. Sobresalían los objetos de plata (2.227 pesos), la carroza (1.200 pesos), un cajón de armería con carabinas y arcabuces junto con un astrolabio (1.000 pesos) y una colgadura de damasco (400 pesos). Los 3.446 pesos restantes correspondían a cuadros (30 cuadros de santos ermitaños, 28 países de Flandes, cristos, santas sibilas, una virgen del Pópolo, etcétera), así como a camas, mesas, sillas, escritorios, espejos, cajones y otros enseres domésticos. Cabe señalar que el valor atribuido a los bienes muebles superaba ampliamente al de los contenidos en las distintas haciendas del magnate. La casa de Parral era el mejor escaparate para que Valerio ostentara su riqueza ante visitantes y autoridades del real de minas $^{53}$. A pesar de la enorme distancia que separaba la provincia de Santa Bárbara de México, el lujo de la morada de Valerio Cortés del Rey era semejante a la de los palacios de la capital novohispana ${ }^{54}$.

En 1670, en el culmen de su poder y ya con una inmensa fortuna, Valerio Cortés del Rey solicitó de la Corona licencia para fundar dos mayorazgos, uno para cada uno de sus hijos varones ${ }^{55}$, así como el título de conde o marqués y la jurisdicción plena de sus dominios, tal y como la habían obtenido con anterioridad Hernán Cortés o el duque de Atlixco en la Nueva España. La real cédula del 2 de octubre de 1674 autorizaba la erección del mayorazgo, pero se pidió mayor información a la Audiencia de Guadalajara, al obispo de Durango y al gobernador de la Nueva Vizcaya porque la Corona quería cerciorarse de su conveniencia. Tuvieron que pasar hasta quince años para

52 Juicio de residencia de Antonio de Oca y Sarmiento, 1669, AGI, Escribanía de Cámara, legajo 396c, n. ${ }^{\circ} 11$.

53 El inventario ha sido transcrito por Baca y Soto, 2006: 103-110.

54 Es lo que constató Gustavo Curiel al analizar el inventario de bienes de su hijo Juan en 1729. Curiel, 1993.

55 Finalmente, su primogénito heredó el conjunto después de que falleciera su hermano menor. 
que se otorgase la escritura fundacional en el real de San José del Parral, el 10 de abril de $1689^{56}$.

Pero el mayorazgo carecía de los privilegios que había pedido su fundador. No comprendía los derechos de justicia solicitados ni el título de nobleza que anhelaba el beneficiario, y la Corona prohibió, además, que sus titulares pertenecieran a una orden militar ${ }^{57}$. Se vinculaba la hacienda de Nuestra Señora del Pilar de Zaragoza con la de San Antonio de Padua y la de San Francisco Javier, es decir, las propiedades que estaban en la frontera norte de la provincia de Santa Bárbara y en la jurisdicción de Cusihuiriachi. Las tres haciendas, muy pobladas a fines del siglo XVIII, habían sido erigidas por el magnate en regiones aún sin colonizar; Nuestra Señora del Pilar y San Francisco Javier acababan de adquirirse ${ }^{58}$.

En 1688, esas tres haciendas y la casa de Parral, que estaban por conformar el mayorazgo, fueron evaluadas en 287.842 pesos $^{59}$. Más de la mitad correspondía a la más septentrional: la de San Francisco Javier. La tierra que le pertenecía no valía gran cosa: los diez sitios de ganado mayor fueron estimados cada uno en 325 pesos, un poco más de la mitad del valor asignado a los diez sitios de la hacienda más sureña de San Antonio. La enorme riqueza de San Francisco Javier se la conferían los animales que pastaban en ella: 50.000 reses, 3.900 ovejas, 1.100 carneros, 5.000 bestias caballares y 300 burras y bu-

56 Porras Muñoz, 1993: 21-22. En ese libro, la fecha de la escritura fundacional (1679) está equivocada. Baca y Soto, 2006: 25, mencionan ese documento con su respectiva referencia que contiene los avalúos de 1688. La real provisión de la Audiencia que autoriza la erección data de 1679. Se opusieron los jueces de Guadalajara a que el rey le concediera a Valerio «título de señorío y jurisdicción perpetua» por temor a que se refugiaran con impunidad en el mayorazgo todo tipo de maleantes y que, en consecuencia, «siendo tan poca gente en aquellas partes podrá suceder que en breve o largo tiempo según se ofrecieren los casos queden desiertos muchos pueblos y poblados». AGI, Guadalajara, legajo 14, r. 3, n. ${ }^{\circ}$ 7. Véase la localización del mayorazgo en el mapa anexo.

57 A pesar de esa prohibición, Juan Cortés del Rey perteneció a la orden de Santiago. Quizá solicitó una licencia especial para su ingreso.

58 No figuran entre las propiedades de Valerio Cortés del Rey en 1670. AGI, Guadalajara, legajo 14, r. 3, n. $^{\circ} 7$.

59 Retomamos a continuación la información contenida en Autos para avalúos de las propiedades que se incluyen en el vínculo y mayorazgo que funda Valerio Cortés del Rey, AHP, 1738b (exp. 4724), transcrito en Baca y Soto, 2006: 95-110. En AGI, Guadalajara, legajo 34, r. 3, n. $^{\circ} 7$ (informaciones de méritos de Valerio Cortés de 1670-1671), el total de los bienes con la hacienda de San Gregorio sumaban 255.000 pesos. Se mencionaban entonces la hacienda de San Antonio (150.000 pesos), San Gregorio (20.000 pesos), Atotonilco (despoblada, sin valor atribuido), Santiago (con beneficio de fuego y azogue y la mina nombrada «El Cabreestante»), la mina «Tejada» en San Diego (60.000 pesos) y la casa de Parral (25.000, sin muebles ni adornos). 
Propiedades de Valerio Cortés del Rey en la provincia de Santa Bárbara

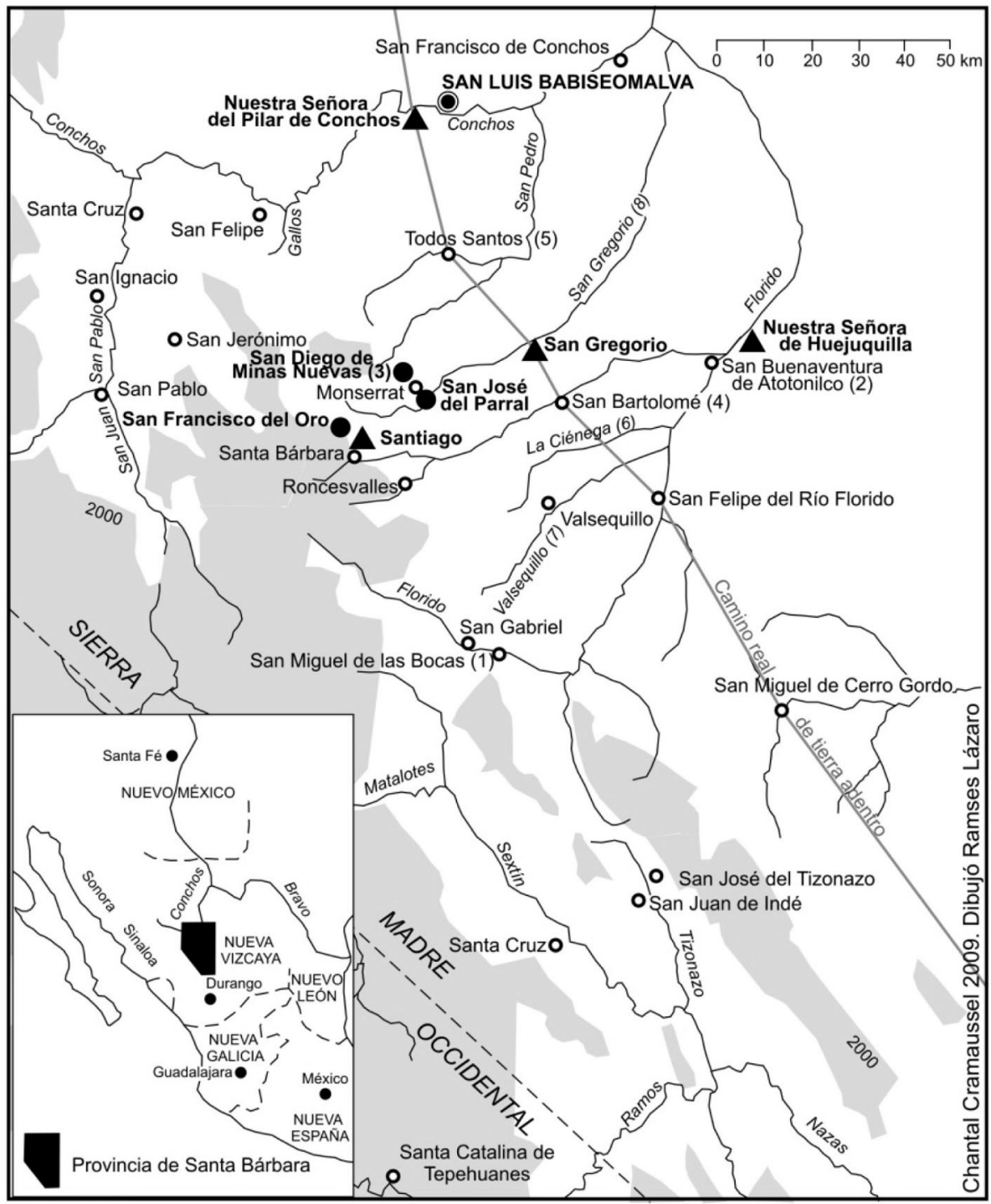

Real de minas donde Valerio Cortés tenía casa o hacienda

Nombre actual de los asentamientos coloniales:

(1) San Miguel de las Bocas: Villa Ocampo

Hacienda minera o agrícola

(2) San Buenaventura de Atotonilco: Villa López

(3) San Diego de Minas Nuevas: Villa Escobedo

(4) San Bartolomé: Valle de Allende

(5) Todos Santos: Cordero

(6) Rio La Ciénega: Primero

(7) Rio Valsequillo: La Concepción

(8) Río San Gregorio: Parral 
rros, que representaban un total de 177.350 pesos (el 96\% del valor total). No cabe duda que el caudillo ejercía bastante control sobre los indios de la frontera, porque el ganado era para ellos un bien codiciado y los robos de animales muy frecuentes. En la hacienda de Nuestra Señora del Pilar del río Conchos, que se destinaba a la agricultura, las tierras y obras de riego, que incluían obras de cal y canto ${ }^{60}$, fueron evaluadas en 30.000 pesos, la capilla en 5.740 pesos y el molino en mil pesos. Junto con los jacales que albergaban la cosecha de trigo y maíz (4.500 pesos), la tierra, la casa, las acequias y el acueducto correspondían a las tres cuartas partes del valor total. En la hacienda intermedia de San Antonio, Valerio Cortés fabricaba jabón y velas de cebo, y tenía un obraje para tejer la lana de sus ovejas. La mitad del valor de esa propiedad (evaluada en 16.720 pesos) lo representaban los esclavos (4.200 pesos) junto con la casa y la capilla (4.500 pesos), mientras el resto lo daban la tierra (6.000 pesos), los aperos, el jabón y la lana que se encontraban en existencia ${ }^{61}$.

A un nuevo potentado sin letras de nobleza todavía, le correspondía seguir las reglas del estamento de los privilegiados y cuidar, vía las alianzas matrimoniales de su descendencia, el destino de la fortuna familiar. Sin embargo, la ambición y la codicia no lo llevó a elegir un marido que perteneciera a las grandes estirpes de la Nueva España para su hija. Valerio prefirió buscar a una persona que pudiera integrar a su casa y que le fuera fiel. En 1671, comprometió a su hija, de quince años ${ }^{62}$, con un criminal, el cual había encontrado refugio en Parral después de haber sido desterrado de la Nueva España por asesinato en Tepeaca y desacato al virrey. El futuro yerno se llamaba Francisco Gómez de Somoza, era de origen gallego y le había brindado protección su paisano, el gobernador Antonio de Oca y Sarmiento. Valerio Cortés del Rey, quien no perdía ninguna oportunidad de enriquecerse, no le dio ninguna dote a

60 La hacienda comprendía un acueducto, construcción excepcional en la región, donde las acequias no eran de cal y canto, sino simples zanjas que había que rehacer cada vez que caían fuertes lluvias. Cramaussel, 2006: 88-89. La existencia de obras de cal y canto muestra, sin duda, el espíritu emprendedor de nuestro personaje. Los peritos encargados de estimar los bienes de Valerio Cortés en 1688 no las evaluaron «por decir no tienen experiencia de tales obras». Baca y Soto, 2006: 99.

61 En 1671, esta hacienda, que producía granos en gran cantidad, estaba estimada en 150.000 pesos y se cosechaba anualmente en ella «4.000 fanegas para arriba» de granos. AGI, Guadalajara, legajo 14, r. 3, n. ${ }^{\circ}$ 7. O su valor fue muy exagerado por las declaraciones de los testigos de Valerio Cortés o esta propiedad decayó significativamente en los diecisiete años siguientes. También pudo haberse considerado como parte de ella la futura hacienda de San Francisco Javier, que no existía todavía en 1671. Los dominios de Cortés del Rey se extendían sobre 18 sitios en 1671, y 20 sitios más las tierras de Nuestra Señora del Pilar, en 1688.

62 Y no a la edad de diez años como lo asenté por equivocación en Cramaussel, 2006: 403. 
su hija como se acostumbraba, sino que, por el contrario, exigió por concepto de arras a Gómez de Somoza la considerable suma de ochenta mil pesos. Los habitantes de Parral criticaban acerbamente ese compromiso matrimonial que se asemejaba demasiado a una venta. Pero la boda se celebró de todas maneras tres años después. Somoza ya había entregado a su suegro cuarenta mil pesos en barras de plata, joyas y mercancías diversas, y otros cuarenta mil en bienes inmobiliarios que constaban de varias casas y haciendas. El día del enlace, Valerio Cortés se contentó con darle al novio una cadena de oro y un anillo, cuyo valor no rebasaba los doscientos pesos, y a la novia un collar de perlas y otro anillo que le costaron doscientos cincuenta pesos más ${ }^{63}$. Para el hacendado, esta unión representaba un negocio redondo, porque, además de los beneficios económicos que había obtenido, se ganaba el apoyo de un yerno incondicional, puesto que no podía prescindir de su protección política una vez concluido el mandato del gobernador. Teresa Cortés del Rey no tuvo hijos y quedó viuda en una fecha que no hemos podido precisar, terminando sus días como monja profesa en el convento de Santa Clara de la ciudad de México ${ }^{64}$.

Valerio Cortés del Rey permaneció sólo veinticuatro meses a la cabeza de su flamante mayorazgo. Le sorprendió la muerte en 1691 a la edad de ochenta y un años, después de sobrevivir largo tiempo a los achaques, dolores de estómago y quebradura de la ingle que mermaban su salud. Su hija Antonia había entrado también al convento, Valerio, su hijo menor, que había destinado al sacerdocio, quedó inválido por apoplejía, y Juan, el primogénito, a sus treinta y siete años no había encontrado aún un partido a su altura. El futuro del mayorazgo, que parecía quedarse sin heredero, estaba, por lo tanto, incierto.

Pero Juan Cortés del Rey se casó finalmente con una integrante de las poderosas familias de la ciudad de Durango, llamada Agustina Antonia de Medina y Castilla. En 1695, cuando la pareja contrajo matrimonio en la capital vizcaína, el novio ya tenía cuarenta y un años y la novia tan sólo catorce. Juan había heredado el mayorazgo a la muerte de su progenitor y contaba con una de las más grandes fortunas del momento. Además, había tratado de aumentar el valor de los bienes heredados de su padre al construir en San Francisco Javier, la hacienda más norteña del mayorazgo, una casa y una presa de cal y canto. En tierras adquiridas por Valerio Cortés en 1688, fundó también una estancia en la jurisdicción de Cusihuiriachi, mineral cuyo auge sucedió al de Parral a partir de 1686. Pero el novio tuvo que entregar de todos modos diez mil pesos en arras y la novia, que era probablemente más pobre pero pertenecía a una fa-

63 Cramaussel, 2006: 403-404.

64 Baca y Soto, 2006: 23, 163. 
milia de abolengo, únicamente unas alhajas. Juan Cortés del Rey trató de seguir, por lo tanto, los pasos de su padre: expandió sus dominios en la frontera con las tierras de los indios gentiles y se casó con una mujer que pertenecía a una familia encumbrada y arraigada en la Nueva Vizcaya. Sin embargo, aunque había incorporado al mayorazgo 35 sitios más de ganado mayor y creado dos nuevas estancias ${ }^{65}$, al final de su vida Juan no contaba con la riqueza de su progenitor, quien había sido beneficiado de la carne y ensayador de Parral durante muchos años en su época de bonanza. En 1719, Juan Cortés del Rey declaraba en su testamento tener cincuenta mil reses alzadas, pero no había podido marcar más de mil. Su fortuna no era ni de lejos semejante a la de su padre: no ascendía en total a más de cien mil pesos y se encontraba endeudado con uno de los grandes comerciantes de Parral ${ }^{66}$.

La biografía de Valerio Cortés del Rey muestra la carrera de un hombre sin relaciones previas en el Nuevo Mundo, ni paisanos aragoneses, que pudo abrirse camino obteniendo cargos civiles, militares y eclesiásticos, y tejiendo alianzas con la oligarquía de una provincia situada en la frontera. Su fortuna inicial la hizo en base a la venta de ganado, pero también acumuló un gran caudal en la minería y adquirió prósperas haciendas de labor. La consolidación de su emporio tuvo origen en su unión matrimonial con la hija de un mercader de plata y en su poder como caudillo militar. No es casual que adquiriera en los años sesenta la mayor parte de sus propiedades, justo cuando la guerra contra los tobosos del altiplano estaba en pleno auge ${ }^{67}$. Valerio Cortés del Rey contaba con un ejército propio, conformado por los sirvientes de sus haciendas, que le eran incondicio-

65 Autos del juicio sucesorio de Bernardo Cortés del Rey, 1728, AHP, 1728b (exp. 4440), citado por Baca y Soto, 2006: 29. Mencionamos ya la primera, llamada La Laguna, en la jurisdicción de Cusihuiriachi, y la segunda era la de San Lucas, ubicada al oeste de Julimes y al norte del río San Pedro.

${ }^{66}$ La evolución del mayorazgo rebasa, desde luego, el tema de este trabajo. Los descendientes de Valerio Cortés del Rey se endeudaron con un comerciante llamado Cristóbal de Orrantia, quien era al parecer el aviador de sus haciendas. Esta deuda ascendía a 16.532 pesos en 1719 y a más de 41.000 pesos en 1728. Dos de las haciendas del mayorazgo fueron arrendadas después por poco dinero y el descuido con las que fueron administradas las llevó al quebranto. Porras Muñoz, 1993: 22. Baca y Soto, 2006: 36-37. Ambos autores insisten también en las pérdidas que registraron las haciendas mineras y la mala administración de los bienes por parte de los descendientes de Valerio. El nieto de nuestro biografiado, llamado también Valerio, trató de obtener ingresos adicionales coludiéndose con un grupo de abigeos. Ortelli, 102 (Zamora, 2005): 163-201.

${ }^{67}$ La guerra contra los tobosos se propagó en 1666 y 1667. Se había rebautizado como «tobosos» a los conchos alzados. Álvarez, 2000: 355-381. En ese mismo periodo, inundaciones, epidemias y una sequía, seguida de una hambruna, afectaron también todo el norte de la Nueva Vizcaya. Para un recuento de las catástrofes ocurridas en esos años, Cramaussel, 2006: 158. 
nales. Trataba también con los indios gentiles que habitaban tierras colindantes con sus propiedades, ubicadas todas en las márgenes de las regiones colonizadas. Se había vuelto, por lo tanto, un hombre clave durante las numerosas rebeliones que azotaron la Nueva Vizcaya durante la segunda mitad del siglo XVII. $\mathrm{Ni}$ siquiera los gobernadores podían prescindir de su alianza. Sin embargo, el destino de Valerio Cortés del Rey fue sólo excepcional por la rapidez con la que hizo fortuna. Los demás personajes exitosos de su época en la provincia de Santa Bárbara ${ }^{68}$, y probablemente en todo el norte de la Nueva España, habían acumulado riqueza y poder de la misma manera.

\section{BIBLIOGRAFÍA}

Álvarez, Salvador, «Minería y poblamiento en el norte de la Nueva España en los siglos XVI y XVII. Los casis de Zacatecas y Parral», Actas del I Congreso de Historia Regional Comparada, Ciudad Juárez, Universidad Autónoma de Ciudad Juárez, 1989: 105-139.

Álvarez, Salvador, «Agricultores de paz y cazadores recolectores de guerra. Los tobosos de la cuenca del río Conchos en Nueva Vizcaya», Nómadas y sedentarios en el Norte de México. Homenaje a Beatriz Braniff, México, Universidad Nacional Autónoma de México, 2000: 355-381.

Baca, Roberto y Soto, Rita, El Mayorazgo del río Conchos (Chihuahua, 1689-1838), Parral, edición privada, 2006.

Cramaussel, Chantal, «Valerio Cortés del Rey. Leyenda e historia», Cuadernos del Norte, 18 (Chihuahua, 1992): 24-28.

Cramaussel, Chantal, Juan Rangel de Biesma. Un descubridor en problemas, Ciudad Juárez, Meridiano 101/Universidad Autónoma de Ciudad Juárez, Gobierno del Estado de Chihuahua, 1992.

Cramaussel, Chantal, «Una oligarquía de la frontera norte novohispana: Parral en el siglo XVII», Bernd Schroeter y Christian Brüschges (coords.), Beneméritos, aristócratas y empresarios. Identidades y estructuras sociales de las capas altas urbanas en Iberoamérica colonial, Frankfurt/Madrid, Vervuert/Iberoamericana, 1999: 85-103.

Cramaussel, Chantal, Poblar la frontera. La provincia de Santa Bárbara durante los siglos XVI y XVII, Zamora, El Colegio de Michoacán, 2006.

Curiel, Gustavo, Los bienes del mayorazgo de los Cortés del Rey en 1729. La casa de San José del Parral y las haciendas del río Conchos, México, Universidad Nacional Autónoma de México, Instituto de Investigaciones Estéticas, 1993.

68 Realicé un estudio prosopográfico de los principales personajes de esta provincia en Cramaussel, 1999: 85-103. 
Griffen, William, Indian Assimilation in the Franciscan Area of Nueva Vizcaya, Tucson, The University of Arizona Press, 1979.

Ortelli, Sara, «Parientes, compadres y allegados: los abigeos de Nueva Vizcaya en la segunda mitad del siglo XVIII», Relaciones, 102 (Zamora, 2005): 163-201.

Porras Muñoz, Guillermo, La frontera con los indios de Nueva Vizcaya en el siglo XVII, México, Fomento Cultural Banamex, 1980a.

Porras Muñoz, Guillermo, Iglesia y Estado en Nueva Vizcaya, 1521-1821, México, Universidad Nacional Autónoma de México, 1980b.

Porras Muñoz, Guillermo, El nuevo descubrimiento de San José del Parral, México, Universidad Nacional Autónoma de México, 1988.

Porras Muñoz, Guillermo, Haciendas de Chihuahua, Chihuahua, Gobierno del Estado de Chihuahua, 1993.

West, Robert, La comunidad minera en el norte de la Nueva España. El distrito minero de Parral, Chihuahua, Chihuahua, Gobierno del Estado de Chihuahua, 2002.

Vallebueno Garcinava, Miguel, Civitas y urbs. La conformación del espacio urbano de Durango, Durango, Universidad Juárez del Estado de Durango/Instituto de Cultura del Estado de Durango, 2005.

Recibido el 2 de septiembre de 2009

Aprobado el 19 de noviembre de 2009

\section{VALERIO CORTÉS DEL REY, FOUNDER OF THE ONLY PRIMOGENITURE IN NUEVA VIZCAYA IN THE $17^{\text {th }}$ CENTURY}

Valerio Cortés del Rey belonged to the minor nobility of the city of Zaragoza. He arrived in the New World in 1621 and reached the highest rungs of society with remarkable speed. While working as a miner, mine guard, assayer, money lender, etc., he acquired many goods and properties in the northern frontier of the province of Santa Bárbara.

At the peak of his success, he obtained a primogeniture that remained in the hands of his descendants until the $19^{\text {th }}$ century. The story of Valerio Cortés del Rey's life exemplifies the great social mobility that could be enjoyed by those from Spain who ventured to seek their fortune in the provincial government of Nueva Vizcaya.

Key words: Nueva Vizcaya, primogeniture, Parral, estate, frontier. 